\title{
EDITORIAL
}

\section{Chemical peeling as a treatment of melasma}

\author{
Shahin Aghaei \\ Iran University of Medical Sciences, Tehran, Islamic Republic of Iran
}

Melasma, which is derived from the Greek word "Melas" (black) is an acquired, symmetrical and macular pigmentation of exposed areas of skin including cheeks, upper lip, chin, nose and forehead. Although it is much more common in skin of color, any race could be affected. Most of cases are women during their reproductive years ${ }^{[1]}$.

Most of the time, no laboratory tests are required for melasma, albeit few studies, which demonstrated mild irregularities in thyroid function tests, especially in melasma during pregnancy or when taking oral contraceptive pills. Wood's lamp exam usually helps to find the pigment particles in epidermis, dermis or in many cases, in both sites $^{[2]}$. Melasma could be hard to cure. Resilient cases or recurrences happen frequently and occur when stringent prevention of exposure to sunlight is disregarded ${ }^{[3]}$.

Although the main mode of treatment would be a combination of topical hydroquinone (HQ) cream along with sunlight exposure prevention, the other choices range from non-HQ topical whitening creams, chemical peeling agents and skin lasers, to some systemic agents like deoxyarbutin, omega 3 and Camellia sinensis (green tea) ${ }^{[4,5]}$. No single agent has shown to be completely efficacious for all patients, though a blend of two or three agents is frequently recommended to attain ideal outcomes.

Superficial peelings agents such as salicylic acid (SA), glycolic acid (GA), tretinoin and Jessner's solution (SA and lactic acid with resorcinol) are testified to provide improvement with the minimum risk of complications. Stronger agents like multiple pass of Jessner's alone, Jessner's and trichloroacetic acid (TCA) mixture, TCA 35\% or phenol cause much more soreness and can potentially worsen the pigmentation ${ }^{[6,7]}$.

More recently, a compound peeling agent named Vi Peel $^{\circledR}$ (a combination of TCA, retinoic acid, SA, phenol, and vitamin $\mathrm{C}$ ) is used to treat a range of skin problems such as pigmentation, fine wrinkles, pores and acne scars in almost all skin types because of the low-dose combination of numerous agents with little inflammation as a side effect. The above agent plus the addition of HQ, kojic acid, and hydrocortisone named "Vi Peel ${ }^{\circledR}$ with Precision Plus" improves treatment of melasma and post-inflammatory hyperpigmentations $(\mathrm{PIH})^{[8]}$.

Skin chemical peeling is a frequently used, rapid, non- invasive and efficacious out-patient therapy that might be used for aesthetic purposes and pigment disorders like melasma. There are specific challenges in using chemical peels on skin of color (skin types IV-VI). For example, the risk of PIH and unusual scarring are high which makes chemical peels possibly harmful ${ }^{[9]}$. Moreover, chemical peeling agents are mostly used to treat epidermal and compound (epidermal/superficial dermal) forms of melasma. Peeling in deep dermal variant often induces unwanted complications such as hypertrophic scars and permanent depigmentation. Clinicians should therefore have enough knowledge and experience of utilising the various peeling agents and their safety, especially on skin of color.

\section{Conflict of interest}

The author declares no potential conflict of interest with respect to the research, authorship and/or publication of this article.

\section{References}

1. Passeron T. Melasma pathogenesis and influencing factors - An overview of the latest research. J Eur Acad Dermatol Venereol 2013; 27(s1): 5-6. doi: 10.1111/jdv.12049.

2. Lawrence N, Cox SE, Brody HJ. Treatment of melasma with Jessner's solution versus glycolic acid: A comparison of clinical efficacy and evaluation of the predictive ability of Wood's light examination. J Am Acad Dermatol 1997; 36(4): 589-593. doi: 10.1016/S0190-9622(97)70248-2.

3. Sofen B, Prado G, Emer J. Melasma and post inflammatory hyperpigmentation: Management update and expert opinion. Skin Therapy Lett 2016; 21(1): 1-7.

4. Taylor CR, Anderson RR. Ineffective treatment of refractory melasma and postinflammatory hyperpigmentation by Q-switched ruby laser. J Dermatol Surg Onco 1994; 20(9): 592-597. doi: 10.1111/j.1524-4725.1994.tb00152.x.

5. Sheth VM, Pandya AG. Melasma: A comprehensive update: Part II. J Am Acad Dermatol 2011; 65(4): 699-714. doi: 10.1016/j.jaad.2011.06.001

6. Sarkar R, Arora P, Garg VK, Sonthalia S, Gokhale N. Melasma update. Indian Dermatol Online J 2014; 5(4): 426435. doi: 10.4103/2229-5178.142484.

7. Faghihi G, Shahingohar A, Siadat AH. Comparison between $1 \%$ tretinoin peeling versus $70 \%$ glycolic acid peeling in the treatment of female patients with melasma. J Drugs Dermatol 
2011; 10(12): 1439-1442.

8. Moubasher AE, Youssef EM, Abou-Taleb DA. Q-switched Nd: YAG laser versus trichloroacetic acid peeling in the treatment of melasma among Egyptian patients. Dermatol Surg 2014;
40(8): 874-882. doi: 10.1097/DSS.0000000000000065.

9. Salam A, Dadzie OE, Galadari H. Chemical peeling in ethnic skin: An update. Br J Dermatol 2013; 169(s3): 82-90. doi: 10.1111/bjd.12535.

Keywords: melasma; skin of color; chemical peeling

Citation: Aghaei S. Chemical peeling as a treatment of melasma. J Surg Dermatol 2021; 6(1): 172; http://dx.doi. org/10.18282/jsd.v6.11.172.

Received: $20^{\text {th }}$ January 2021; Published Online: $27^{\text {th }}$ January 2021

*Correspondence to: Shahin Aghaei, Roonik Skin Clinic, \#78, Asad-abadi Ave., Tehran, Islamic Republic of Iran, shahinaghaei@yahoo.com 